\title{
Reducing the light pollution in settlement units areas - comparative case studies
}

\author{
Agata Łopuszyńska ${ }^{1, *}$ \\ ${ }^{1}$ Wrocław University of Science and Technology, Faculty of Architecture, Chair of Urban Planning \\ and Settlement Processes, B. Prusa 53/55, 50-317 Wrocław, Poland
}

\begin{abstract}
Dark-sky areas are a form of night landscape protection and reduction of light pollution (LP), but also a new direction of inhabited and urban areas development. Yet still the lack of social awareness of artificial light at night (ALAN) exposure issues is widespread. While the technical aspects of outdoor lighting modernization used for reduction are recognized and continuously elaborated, there is no specific scheme of the dark sky communities formation processes. In contrast to isolated areas of dark-sky protection, they are a challenge due to the accumulation of various functions and interests or spatial conflicts. The article is an attempt to determine how and why particular programs work or fail to work on the examples of the Polish village of Sopotnia Wielka and the Scottish town of Moffat. It seems that the legal factors are decisive, but other important aspects like social or planning come to the fore.
\end{abstract}

\section{Introduction}

The rapid development of the artificial lighting usage associated with lowering costs of electricity, began to result in negative phenomena, which were called light pollution (LP). The increase of the night-sky brightness as a result of expansion of urbanized areas [1] reflects not only the scale but also the approach to lighting planning of such areas. At present, the problem concerns not only developed agglomerations as the excess of light is severe even for small settlement units [2].

Limiting the phenomenon has a short history, despite the latest gain of publicity given to LP issues. However, there are places where conscious steps have been taken to protect the night sky darkness. At present, the generally recognized quality of these places involves obtaining the official status. Designation of such areas is carried out by the only organization of its type in the world: the International Dark-Sky Association (IDA) [3]. Since 2001, IDA has been pursuing the Dark Sky Places program, encouraging the preservation and protection of dark-sky areas.

Status, however, is one of the ways to reducing LP in residential areas; there is no universal method or process. This paper is to learn what kind of solutions settlement units apply at the very beginning of such areas operation.

\footnotetext{
* Corresponding author: agata.lopuszynska@pwr.edu.pl
} 


\subsection{Reduction of an excess brightness}

In Poland, none of existing dark-sky areas has obtained IDA status, nor has yet applied for it. However, there are places that strive for it, slowly improving its lighting system and changing public perception of LP. Although Polish law does not formally consider light as a source of atmospheric pollution, bottom-up activities are undertaken in several places [4].

Due to the form of land use, two types of such areas can be distinguished: protection and restoration of darkness. Protection mainly includes preventive activities in areas where the night sky condition is very good, aiming to maintain its excellent quality. This quality is measured by the brightness level and visibility of astronomical objects, especially the Milky Way. These unpopulated areas with negligible or no lighting provide the opportunity of experiencing a "true night". In turn, the restoration of night darkness refers to the areas within which the actions taken are aimed at reversing the negative effects of irrational lighting policy. The night sky darkness quality does not have to be perfect, but significantly improved by conscious minimizing LP. This applies to inhabited areas: entire urban communities, rural or suburban zones or certain districts of a city. Such zones have not covered areas of big cities so far.

While the technical rules or legal regulations on limiting LP are relatively simple (it depends, however, on the stringency of applied solutions), it becomes more complicated in inhabited areas. The difficulty of making specific changes consists of both formal and social reasons. In contrast to areas with a homogeneous structure, such as isolated dark-sky parks, they are a field of contradictory functions and interests, as well as numerous spatial conflicts. Moreover, these are the places most polluted by artificial light.

\subsection{Dark Sky Communities}

The "International Dark Sky Communities" occupy a special place among five of the IDAcertified areas because they include legally organized cities, towns or municipalities. There are currently 18 designated areas of this type, with only 5 of them located outside of the US. To achieve this status, rigorous conditions must be met [5]. First of all, there must be shown a special care for the quality of outdoor lighting, both public and private, limiting upward emission. In addition, consistent enforcement of implementation and lighting planning, education in the field of LP and the recognition of the community for the darksky preservation are required. Although knowledge of light pollution originates from astronomy, the ALAN issues are no longer just a matter of stars visibility. Light is part of modern societies, which led to the disruption of the natural day-night (light-dark) cycle of a significant part of the population. The state of affairs gives rise to concerns about hazardous impacts of exposure to certain types of artificial light at night in urban space [6]. Dark-sky preservation constitutes a prospect of developing a certain lighting culture and restoring the night landscape in the cities. This does not mean, however, depriving the community of the benefits of using light. The compromise is currently difficult to work out, and attempts to its obtention are presented in undermentioned case studies: Sopotnia Wielka and Moffat.

\section{Methods and material}

\subsection{Aim and scope of the study}

The primary aim of this article is to analyse the course of LP reduction processes in the settlement units areas. The study consists of the most advanced place in dark-sky protection 
in Poland - village of Sopotnia Wielka, and the Scottish town of Moffat, which already obtained IDA status. The timeframe of the research covers mostly the last decade, when these places started to be formed, and a few references to the past and legal background. The said areas were examined in terms of the factors that influenced these processes along with the causes, consequences and the scope of the dark-sky protection in residential areas. The workload, tools and efficiency of the described activities were also assessed.

\subsection{Research hypothesis}

Despite the low public awareness of the impacts related to ALAN, residential areas are likely to succeed in reduction of LP. However, the compromise between dark-sky preservation and widespread urban lighting is difficult to attain. It seems that legal issues are the most limiting or stimulating in this field. Still, due to the novelty, complexity and the multidimensional character of processes as well as phenomenon impacts, social and technical factors come to the fore.

\subsection{Methods}

The comparative case study method was adopted in the article. The choice of cases for the study was based of similarities in the main features of the areas and the shared aim of darksky preservation. However, they were compiled on the basis of differences in the course of these activities and certain corresponding conditions. Areas of small settlement units with a similar number of inhabitants were chosen: village and town. They differ in the ways and means of enforcing spatial policy mainly for legal reasons and, what is related, to financial matters. The research includes literature review in the field of the LP phenomenon and its impacts as well as the analysis of planning documents, legal acts and others related to specific areas including reports, documents, press notes, graphic materials and official websites. Due to the need of understanding the background, interviews and unpublished materials were also used.

\section{Processes of light pollution reduction}

\subsection{Sopotnia Wielka}

Sopotnia Wielka is a borderland village in the administrative district of Jeleśnia, within Żywiec County, Silesian Voivodeship. It has about 2000 inhabitants and the predominant sectors of carpentry and tourism. The first successes in the area of LP reduction have occured in the 1990s. Seeking for dark skies resulted from the needs of astronomical observations - as a grassroots initiative of the then 'Polaris' astronomical club.

Sopotnia is a rural area, but rather densely populated, hence twenty years ago nuisances of excessive outdoor lighting started to be noticed. Initially interim activities changed into a plan of succesive improvement of the night sky quality. As a result of concluded contracts with village leader office and the commune office, street lighting has been shut-down in areas of observations, since 2002. It included 42 lamps that were switched off, throughout the year, from midnight to $4 \mathrm{am}$. These steps were accompanied by a social information campaign. However, it took several years to bring about lasting changes in the lighting of Sopotnia Wielka. Since 2009, cross-sectoral arrangements have been sought to increase the scope of reduction. In 2011, more than 150 public street lamps were replaced with new ones of flat luminaires, appropriate booms and power reducers (in accordance with IDA standards) [7] (Fig. 1.). The lamps are also dimmed by $20 \mathrm{~W}$ in the late night hours. 
In addition, several residents consciously replaced their property's lighting with the proper ones. It has not been possible to modernize the church's illumination, which is the largest local source of pollution, for social reasons. Still, mechanical shutters of lamps are used there when needed. In November 2011, the first dark sky protection area in Poland was officially inaugurated.

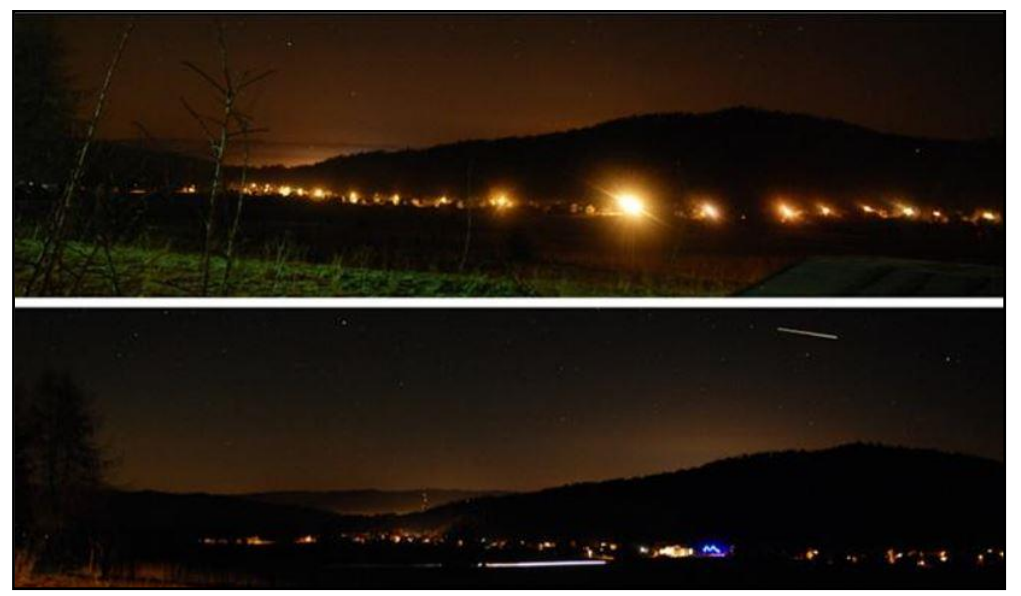

Fig. 1. Panoramic views of Sopotnia Wielka before and after lighting modernization [7].

The investment was co-financed from the Rural Development Program 2007-2013 and from the Poland-wide campaign ' $1 \%$ of tax for astronomy' [7]. The whole venture was enabled by the development of a local development strategy for the associated group of Żywiec regions. The current Local Development Strategy [8] emphasizes the precursory role of dark-sky preservation as an important element of environmental protection and cultural heritage. It is also an important part of natural landscape conservation, stimulating tourism as the key economic activity in the region. Dark-sky preservation, however, currently operate on the basis of agreements and arrangements, which are not legally protected in the light of Polish regulations. There is always a risk of investments incompatible with the requirements that could disturb conscious reduction.

Conscious changes in the lighting policy of the village resulted with savings in the municipal budget. The lighting costs were reduced by approx. 40\% per year (in 2012) [7]. Sopotnia still has no system for measuring or reporting on sky brightness. Currently ongoing work to install measuring station will increase the chance for the further changes.

Positive results were also observed in the economic and social sphere of the Jeleśnia commune. Dark-sky protection has contributed to the development of innovative forms of tourism. Sopotnia Wielka currently has technical and recreational infrastructure set up for the so-called astrotourism. Apart from favorable conditions for astronomical research, accommodation base and special areas of observations, independence from weather conditions was ensured. Among others, a multiplanetarium and didactic infrastructure were created [9]. Therefore, this place is not a static platform for observation by professionals, but a field of interaction, knowledge and passion for the dark skies.

Sopotnia Wielka has become the absolute precursor in combating light pollution across the country. However, it was a long and laborious process that required gaining social understanding and making agreements with decisive authorities. Efforts in this area were conducted on their own, but proved to some extent satisfactory. Without favorable policies at the regional and national levels and without further funding, several projects have been completed. Sopotnia still has a positive influence on social awareness and real changes not only locally but all over Poland. 


\subsection{Moffat}

In February 2016, the first dark city in Europe was announced. Moffat, a town of 2500 population, is located in southwestern Scotland. Historically associated with wool and spa tradition, is still developing tourism as the largest field of the economy. The city is located an hour's drive from the first dark-sky park in the UK, Galloway Forest, created in 2012. The above factors have led to striving for the status of international dark-sky community.

In 2013, the Dumfries and Galloway authorities have felt the benefits of the dark-sky park established a year ago and decided to modernize the whole region in this field [10]. In almost every city, the lighting has been replaced to prevent an above the horizon light emission, disallowing its uncontrolled escape. The municipal office of Moffat supported the one of the residents' idea to seek even more - an IDA status. It was decided to replace the old lighting due to the energy efficiency and carbon dioxide emissions reduction as postulated by the government. Local authorities were also allowed to apply for the dark sky community certificate. It was hoped that it would have a positive impact on tourism in the town, which significantly decreased in the winter season. The challenge was to meet all the formal requirements of such status. It included a comprehensive lighting policy that complies with technical and administrative guidelines. It was also necessary to have a citizen and authority support and the local community involvement in dark skies and quality lighting education. Also, a city applying for the certificate must have already suceeded in reducing the sky glow and maintain a pollution measurement program [5]. Therefore, measuring points were opened a bit earlier in the city, and its space was documented before modernization. The venture began with the planning of lighting throughout the city. A large lighting master plan was developed that exhausted all aspects related to the light in the city. The document covered mainly the recognition of the LP phenomena in Moffat, economic, spatial and technical aspects. The idea of meeting the IDA guidelines was presented, planning the modernization of all types of outdoor lighting: from public to commercial. The zoning of the town was made within which acceptable levels of brightness are differentiated, taking into account the conditionings of the entire county [11]. The plan also included a detailed selection of proper luminaires and light sources.

Practical activities began with informing the local community about planned changes. Residents were presented with visualizations of the differences expected by lighting retrofitment. The existing street lamps were used for only three years, but they turned out to be too bright. According to the municipal office estimates, they contributed to the waste of half the amount of light emitted. The new lamps were installed in 2013, within just a few months. It was decided to use energy-saving LED technology. The lamps of streets and access roads were replaced, as well as external illuminations of buildings (Fig. 2). At the expense of the region, all other street lamps that were especially harmful, in pursuance of the new lighting policy, were also removed [12].

Dumfries and Galloway council has incurred the cost of 240 '000 pounds including purchase and installation of lamps, design and IDA application fees. The investment is expected to pay within 8 years and bring further savings over the anticipated 20 years of lamps lifetime. Analyzes already indicate a reduction of: energy consumption by $50 \%$, carbon dioxide emission by $55 \%$, light pollution by $99 \%$, lighting maintenance costs by $33 \%$ [10]. These values exceeded previous predictions. Improvement of safety and benefits for tourism has also been demonstrated. Due to these results, similar activities are planned in the whole region. Together with the Galloway Forest and Moffat parks, it would constitute an area of more than $6000 \mathrm{~km}^{2}$, forming the only such enclave of dark sky in the world. The area aspires to create the best place to observe stars in Europe. It can be concluded that the investment in reducing LP has improved the quality of inhabitants 
life. Improvement in public space aesthetics, quality of sleep and the sense of comfort of residents was also noticed.

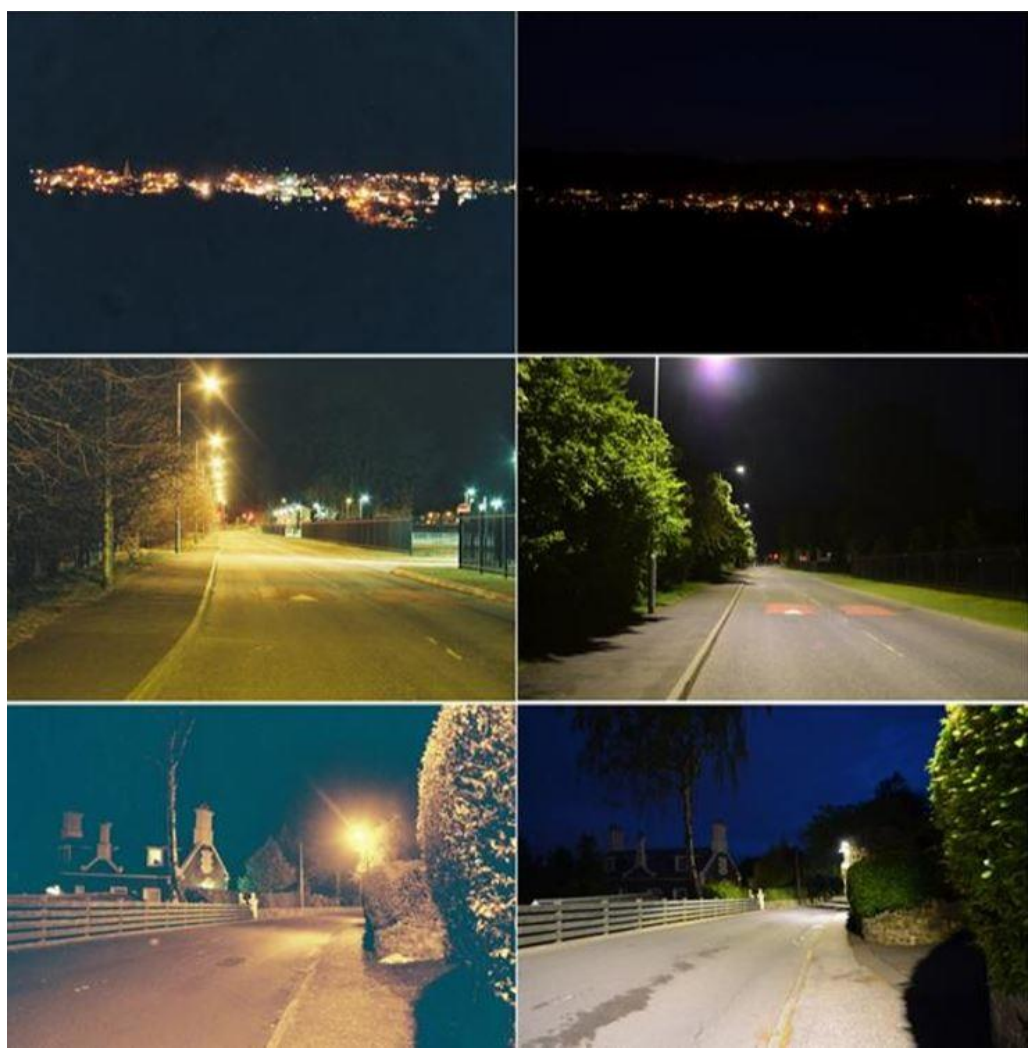

Fig. 2. Comparative photographs of Moffat public space before and after lighting modernization [12].

\subsection{Analysis of influencing factors}

Recognition of the background is important for understanding the phenomena and assessing the scale of successes or failures of both analysed areas. Despite significant differences in the legal and social conditionings, it is possible to identify the key elements.

As at present in Poland, also in Scotland, LP was marginalized in comparison to other sources of contamination. In England and Wales, the excess of light was formally recognized as a civilization problem in 2006 [13]. In 2008, the Scottish Government incorporated artificial light into the legal list of pollution sources. Light intrusiveness and high energy consumption were called the most serious pollution features [14].

Currently, there are no legal regulations in Poland that would allow permanent protection of the nocturnal landscape. Environmental law does not address to lighting issues [15]. Until 2009 it was impossible to apply for any limitation of light emission. The amendment to the ordinance of the Ministry of Infrastructure [16] provides for limiting the lighting intensity, but only for windowed facades. Only this record allows treating light as a nuisance to space users in the form of improper lighting fixtures. In the absence or lack of legal regulations, making changes in the lighting system is much more difficult, not only for formal reasons.

In the case of Sopotnia Wielka, there are alternative solutions like inclusion of village area into the landscape park zone. It is possible by the application of a local regulation 
tightening the requirements for all of outdoor lighting - dark sky as an element of landscape conservation. However, this requires essential social and political support, which is currently not the case. It is also an obligation to replace all inappropriate light sources, including private and commercial ones, to what not everyone is convinced of. In Moffat, the legal regulations contributed to the increase of speed and efficiency of the procedure, the comprehensiveness of actions and their funding. In Poland, despite having a satisfactorily effective legal alternative, financial and social issues are a greater limiting factor than legal ones. As a result the concluded compromise agreements are not a guarantee of permanent and effective reduction of the LP. The law could sort of influence the approach to the problem, and financing - the negative social moods, because the residents would not feel the pressure of changes at their own expense.

The current Local Development Strategy [8] is the only planning document officially taking a stance on dark-sky aspirations of Sopotnia Wielka. As part of its implementation, it is possible to realize the projects, selected through a competition, in the field of social and economic recovery. The strategy covers many municipalities, areas and stakeholders, and therefore has a narrowed budget and scope of actions. The Exterior Lighting Masterplan for Moffat is in turn an example of a comprehensive document including overall analysis of the area and an interdisciplinary action plan as part of the lighting system retrofitment.

The role of leaders in both ventures must be not disregarded. From the very beginning, Sopotnia Wielka has become a significant dark-sky place due to the local group of astronomy enthusiasts. A whole social program promoting astronomy, education of youth, and now also advisory services in the framework of reducing LP lighting technology, have arisen over time. In Moffat, one of the residents, who was professionally involved in dark-sky projects of other places, took a role of leader. His experience and awareness of the then poor city lighting met with the approval of local and regional authorities, because at the same time they were looking for a way to implement energy savings and reducing emissions policies.

\subsection{Discussion}

In spite of a small number of dark-sky areas in Europe, it was possible to successfully examine places of features that allow a satisfactory comparison. It could be useful source of information and guidance in terms of spatial planning, in the time of massive modernization of urban lighting. Especially now, when the brightness of populated areas increases dramatically as a consequence of energy efficiency policy.

The lack of symmetry in the form of sources and material can be considered as limiting in the study: in Moffat, mainly formal studies, in Sopotnia, more soft and unpublished data. This results not only from the access to these data, but also reflects the nature of the presented processes: planned, efficient, multidirectional actions against the bottom-up, long-term social initiative based on smaller and often interim projects.

\section{Conclusions}

Regulations limiting light pollution in urban areas are still of small-scale and there are no developed schemes for them yet. However, their specific elements are often duplicated, not only because of the primary goal, but also because of IDA requirements. At present, astronomy is the main incentive for lighting quality, so for to the stars visibility restoration. A bottom-up initiative leader is also needed, even if it is fully supported by the authorities. The Moffat treats applied changes as investments and the prospect of future savings, with a simultaneous social benefit - such favour is the result of the symbiosis of profits. In the case of Sopotnia, modernization is perceived as a potential opportunity for the area 
development, but without much support from the authorities, still unnecessary inconvenience for the community. The attitude of the authorities and society also partially reflects the legal situation.

The legal regulations create the opportunity to broader actions, also in terms of funding and public awareness, and further local, facilitating the overall management of the project. It is important but not always decisive. Inhibitions, of decision-makers as well as residents, often originate from conflicting interests and reluctance to change. Funds can, however, eliminate bad social attitudes and impact the lighting habits. When all interests come together, mutual gains can be obtained: future budget savings, lighting quality and dark sky. Finance and ecology of the urban environment is one of the louder arguments in developed regions. It takes time and the right development directions to achieve such a state.

Processes of light pollution minimizing in inhabited areas may therefore have to be targeted to more non-astronomical lighting issues, that directly affect the largest number of, still not fully risk-aware, people. The cultural value of starry-skies landscape restoration is not convincing for the modern community. The dominant approach to lighting design based on energy efficiency is also hazardous, as well as the transfer of daylight vision comfort indicators to the night time conditionings. However, aspects of the long-term effects of artificial light at night exposure are still omitted.

\section{References}

1. M.F. Walker, Publ. Astron. Soc. Pac. 89, 405-409 (1977)

2. Ch.C.M. Kyba et al., Sci. Adv. 3, 11 (2017)

3. IDA, International Dark Sky Places, http://www.darksky.org/idsp/

4. P. Nawalkowski, Dzikie życie 11, 233, 11-13 (2013)

5. IDA, International Dark Sky Community Guidelines (IDA, Arizona 2015)

6. K.M. Zielińska-Dąbkowska, Nature 553, 274-276 (2018)

7. https://www.ciemneniebo.pl/pl/obszary-cn-000/cn-001-sopotnia-wielka-jelesnia

8. LDG Żywiecki Raj, Strategia Rozwoju Lokalnego Kierowanego przez Społeczność obszaru LDG Żywiecki Raj na lata 2016-2023 (Załącznik nr 1 do Uchwały Zarządu nr 7/2016 z dn. 23.05, 2016)

9. http://www.polaris.org.pl/index.php?option=com_content\&view=category\&id=77\&Ite $\operatorname{mid}=72$

10. Mofat Dark Skies Project, LED Case Study (Dumfries\&Galloway Council 2013)

11. J.H. Paterson, Moffat - Dark Sky Community External Lighting Master Plan 2015

12. An application to the International Dark-Sky Association, Moffat International Dark Sky Community (Dumfries and Galloway Council 2013)

13. The City of Edinburg Council, The State of the Environment Audit: Light Pollution

14. West Lothian Council, Suplementary Planning Guidance, Controlling light pollution and reducing lighting energy consumption

15. Prawo ochrony środowiska, Dz.U.2001 Nr 62 poz. 627. Art. 3, pkt. 4

16. Rozporządzenie Ministra Infrastruktury z dnia 12 marca 2009 r. w sprawie warunków technicznych jakim powinny odpowiedać budynki i ich usytuowanie, Dz.U. $2009 \mathrm{Nr}$ 56 poz. $461 . \S 293$ ust. 6 